\title{
A Small Macroeconometric Model of the Lithuanian Economy
}

\author{
Rimantas Rudzkis \\ Institute of Mathematics and Informatics, Lithuania ${ }^{1}$ \\ Virmantas Kvedaras \\ Vilnius University, Lithuania ${ }^{1}$
}

\begin{abstract}
A small vector error correction model of the Lithuanian economy is presented aimed at forecasting and explaining the macroeconomic fluctuations. Various aspects of model building are discussed in the light of specificity of the Lithuanian economy. The adequacy of the model is evaluated using in- and out-of-sample empirical data. The model is used to produce short-term forecasts of the main Lithuanian macroeconomic indicators evaluating, in addition, the impact of the European Union funds on the growth.
\end{abstract}

Keywords: Econometric Modelling, Cointegration, Forecasting, Macroeconomic Fluctuations.

\section{Introduction}

Fast transformations of the Baltic countries have matured recently into joining the European Union (EU) in May 2004 and the exceptional growth of the Baltic economies. In Lithuania, particularly, the economic growth has exceeded 6 percents per year since 2001 making it the leader among not only the Baltic countries, but also the whole Europe. Will this rapid growth of Lithuanian economy continue? How much and in what manner are the EU funds expected to add to it, as Lithuania is the net receiver of the funds? These questions are approached in the last section of the paper using the macroeconometric model developed.

The first part of the paper develops a small conditional Structural Vector Error Correction Model (SVECM) aimed at explaining the main indicators of macroeconomic fluctuations in Lithuania, based on the statistical theory of cointegration and respecting the specific features of the Lithuanian economy, e.g., small and very open economy in transition with the currency board arrangement (CBA). The extensive in- and out-of-sample adequacy evaluation is applied in order to avoid potential problems related to short data series as much as possible. The long-run exogeneity testing of the variables, treated in the conditional SVECM as exogeneous, has been performed.

The findings are that, in 2005, without the EU funding the Lithuanian economy would be expected to slow down the pace of growth to 4.4 percents per year as measured by an increase in the Gross Domestic Product (GDP). But the demand side effects of the EU funds are expected to add to the growth above two percentage points resulting, in total, in 6.6 percent increase in GDP.

The paper is organized as follows: Section 2 discusses the specific features of Lithuanian economy, availability of data and their impact on choosing the methodology of mod-

\footnotetext{
${ }^{1}$ The Lithuanian State Science and Studies Foundation supported the research, project No. C-03004.
} 
elling. Section 3 tackles the problem of specifying the conditional SVECM model. Section 4 presents the final estimated model and evaluates its stability. Section 5 then describes the results of forecasting and simulations of the impact of the EU funds on the Lithuanian economy.

\section{Specific Aspects of Building the Lithuanian Macroeconometric Model}

In general, a macro-econometric model is a system of econometric equations and identities, describing the macroeconomic functioning of a country. However, the structure and properties of macro-econometric models may vary substantially and the model building methodology can differ dependent on the aims of modelling, the available data, and the modelled economy. This section investigates the economic and econometric modelbuilding alternatives in the case of developing the Lithuanian short-term forecasting model.

\subsection{Economic Considerations}

Usually the short-term forecasting models are based more on the traditional (Keynesian) demand side approach. Many models for countries in transition lean on the demand side even when used for longer-term forecasting or simulations, see e.g. Basdevant and Kaasik (2003), De Haan et al. (2001), Weyerstrass et al. (2001) for the Estonian, Macedonian, and Slovenian models, respectively. This is due to several reasons. First, one-sided models are simpler and the modelling tradition in smaller countries in transition is quite new. Second, the available data on capital stock of the countries in transition are very poor (e.g. see Basdevant and Hall, 2002) or missing at all, like in the case of Lithuania. Third, there are economic reasons for concentrating on the demand side modelling in the countries in transition.

There is almost a consensus on the conclusion from the growth studies that the 'traditional' growth determinants, related to the growth of factor inputs, have not had any significant influence so far on the growth process in the countries in transition (see Havrylyshyn, 2001 ,for a survey). In transition economies, the demand-side-driven growth itself can induce the productivity gains in the economy through diminishing allocative inefficiency and the process of learning by doing. The effect is likely to be even more important, the more open an economy is, because openness also creates additional impulses for growth through foreign direct investment induced "know-how" acquirement and the export induced scale economy effect. Therefore the supply side constraint is looser in economies in transition and the stress should be put on modelling the demand side.

In Lithuania the demand side modelling has its own specific features, as the Lithuanian economy is a small open economy with the currency board arrangement. The small size together with the fixed exchange rate mean that interest rates are linked to the interest rate of the currency base country through the uncovered interest rate parity; the open and small economy also implies that foreign prices are exogenous; and the currency board arrangement means that money supply is endogenous - as distinct from many other countries, the Bank of Lithuania is impotent to conduct any monetary policy. Under these circumstances 
it could be seen that the money market equilibrium follows the goods market equilibrium, as the money amount adapts to the exogenously given interest rate and a certain activity level. For modelling it means that, other than in many other countries, there is no need to build a monetary sector block in the Lithuanian macroeconometric model. In addition, recalling that the supply constraint is rather non-binding, the total macroeconomic equilibrium will be basically defined in the market of goods and services. As a consequence, the principal attention in modelling the Lithuanian economy should be paid to the demand side, and, as the domestic demand growth of a small economy is usually relatively limited through the balance of payments constraint (see McCombie and Thirlwall, 1994), export is the key variable for the long-run demand expansion.

In Lithuania firms are very export oriented, - in manufacturing the exported production makes up 60 percents of gross output. Because of the sunk costs of entering the foreign market (see Sutton, 1991) and a very limited absorption capability of the domestic market firms keep exporting even when export prices are relatively low compared to domestic prices. The decision sequence of firms is, therefore, to supply the foreign markets first and then to balance the domestic market through the pricing mechanism, e.g., when exports increase, the amount of domestically available goods decreases increasing thereby their price. All this allows us to expect not only the export prices, but also the volume of exports to be exogenous in Lithuania.

\subsection{Econometric Considerations}

The key difference from the methodological econometric modelling point of view is whether modelling leans on the structural or reduced form. In the Cowles commission approach (see, e.g. Favero, 2001), the modelling starts from the structural form implied by a certain economic theory, and then the reduced form is only a means to express distributional characteristics of the process and to analyse the identification problem of the structural form. In this approach, the underlying assumption is that the economic model is the correct one, and the only task left then is obtaining estimates, possessing some desirable finite sample or, usually, asymptotic properties. A different viewpoint is taken in the methodology of London School of Economics or the so called Hendry methodology that points to the reduced form as a more general structure of a model, which enables testing the validity of over-identifying restrictions usually implied by the predictions of economic theory (see Hendry, 2000). In the Hendry approach, therefore, the economic theory is not taken as the truth, but rather just as a guideline that needs to be carefully tested, starting from the general reduced form structure - usually a Vector Autoregression (VAR) model - and, if findings are consistent with the data, restricting the reduced form to obtain certain more restricted economic structures.

The presented discussion then leads to the following conclusion. Since the economic theory for the transition economies is rather scarce and predictions quite loose (see Qin, 2000, for a survey), an application of the Hendry approach to construct an empirically adequate model would seem to be superior over the structural view. This approach is however data intensive, as it starts from an unrestricted VAR model. During the last decade of the last century, the systems (including the statistical one) of the countries in transition have changed dramatically. In Lithuania since 1995 more or less reliable 
and comparable macroeconomic data have been mostly available due to the change in the national accounting system in 1994. Therefore the main problem for econometric modelling, even when using quarterly data, is the short data sample. About thirty five observations are now available and this highly restricts the opportunities for applying the desired Hendry methodology, because relatively reliable estimates of the parameters of unrestricted VARs, the VAR lag order being four (for quarterly data this lag order seems quite reasonable due to seasonality and yearly planning period effects), could be obtained in the systems of three variables, at best. The lack of data, therefore, pushes the use of the traditional structural modelling approach, at least as a starting point in splitting a larger set of variables into smaller subsystems.

\section{The Statistical Model and its Specification}

Because of the described scarcity of data, the traditional modelling approach is applied in developing a model for the Lithuanian economy starting from the structural rather than reduced form. In particular, the conditional SVECM is employed (for reasoning, why this kind of model should be relevant to the countries in transition, and particularly, to Lithuania see Rudzkis and Kvedaras, 2004). Let $Y_{t}$ denote the vector of $m$ endogenous variables and $X_{t}$ be the vector of $k$ exogenous variables. If all the $n$ components of a vector $Z_{t}^{\prime}=\left(Y_{t}^{\prime}: X_{t}^{\prime}\right)$ are integrated of order one $\left(\forall i Z_{i t} \sim I(1)\right)$, and there are $r(r<n)$ stationary linear transformations $\beta^{\prime} Z_{t}$, then a multivariate VARX process $Y_{t}$ could be expressed as the conditional SVECM (see Boswijk, 1995).

Assuming that the same identification restrictions apply to the long run (levels of variables) and the short run (changes of variables), the standard conditional SVECM reduces to the following

$$
\begin{gathered}
\Gamma Y_{t}=B X_{t}+u_{t}, u_{t} \sim I(0), \\
\Gamma \Delta Y_{t}=A u_{t-l}+B \Delta X_{t}+A(L) \Delta Z_{t}+D_{t}+\varepsilon_{t}, \varepsilon_{t} \sim \text { n.i.d. }\left(0, V_{\varepsilon}\right) .
\end{gathered}
$$

where $\Delta$ denotes the first order difference transformation $\Delta Y_{t}=Y_{t}-Y_{t-1} ; \Gamma$ is a normalized matrix of contemporaneous relationships of endogenous variables; the disequilibrium error term component $A u_{t-l}=\Pi_{Y} Y_{t-1}-\Pi_{X} X_{t-1}$ defines the stationary linear transformation of cointegrated variables; $A(L)=\sum_{l=1}^{p} A_{l} L^{l}$ is the lag polynomial; $L$ is the lag operator $\left(L^{l} Z_{t}=Z_{t-l}\right) ; D_{t}$ is a deterministic part of the model consisting of constant, trend, and dummy variables; $\varepsilon_{t}$ is a multivariate white noise error term with the diagonal covariance matrix $V_{\varepsilon}$. Given that equation (1) is identified, the conditional SVECM is identified as well due to $\Pi_{Y}=A \Gamma$ and $\Pi_{X}=A B$. It should be noted that the same structure of matrices $\Gamma$ and $B$ instead of their equality in the short and long-term relationships would suffice for the identification of $\Pi_{Y}$ and $\Pi_{X}$.

In developing the model, the economic specification is defined first by imposing the respective zero restrictions on (1) and (2). After defining the potential economic relationships, the statistical testing is performed, whether the theoretical sets of variables in 
levels represent the cointegration relations. Further, the identified cointegration combinations are utilized to form the conditional SVECM, and the dynamic part of the model consisting of the first changes is formed leaning on the economic specification and, additionally, on the statistical forward selection procedure. Finally, it is tested for the long-run exogeneity of the variables assumed to be exogenous in the model.

\subsection{Economic Specification of Equations and the Data}

Preliminarily, fourteen variables were defined (the notation of the logarithm of a respective variable, except interest rates that are not transformed, is shown in brackets): GDP $(Y)$, GDP deflator $(P)$, employment $(L)$, exports $(X)$, export price index $(T)$, import price index $(Z)$, imports $(M)$, interest rates $(R)$, labour force $(F)$, private $(C)$ and public $(G)$ expenditure, gross investments $(I)$, gross output $(O)$, and wages $(W)$. Based on economic reasoning and the specific features of the Lithuanian economy (the economic theory background for the presented specifications is presented in Kvedaras (2004), the initial economic relations were specified that are summarized in Table 1 (the dependent variables are listed on the left, explanatory variables are provided in the first row, and the sign indicates the expected character of influence, i.e . "+" - positive, "-"- negative).

Table 1: Economic specification of relationships

\begin{tabular}{|l|l|l|l|l|l|l|l|l|l|l|l|l|l|}
\hline Economic specification & $C$ & $G$ & $I$ & $M$ & $O$ & $P$ & $W$ & $L$ & $\mathrm{~F}$ & $\mathrm{R}$ & $\mathrm{X}$ & $\mathrm{Z}$ & $\mathrm{T}$ \\
\hline$C=f(I, L-F, O, R)$ & & & - & & + & & & + & - & - & & & \\
\hline$G=f(O, R)$ & & & & & + & & & & & - & & & \\
\hline$I=f(G, L-F, O, R, X)$ & & $+/-$ & & & + & & & + & - & - & + & & \\
\hline$M=f(I, O, P-Z, X)$ & & & + & & + & + & & & & & + & - & \\
\hline$O=f(C, G, I, P-Z, X)$ & + & + & + & & & - & & & & & + & + & \\
\hline$P=f(O-L, T, W, Z)$ & & & & & - & & + & + & & & & + & + \\
\hline$L=f(O, P, R, W)$ & & & & & + & + & - & & & + & & & \\
\hline$W=f(L-F, O-L, P)$ & & & & & + & + & & $+/-$ & - & & & & \\
\hline
\end{tabular}

There are five exogenous variables bold faced in the table: labour force $(F)$, interest rate $(R)$, exports of goods and services $(X)$, price index of imports $(Z)$, price index of exports $(T)$.

As could be seen in Table 1, in all behavioural equations the gross output $(O)$ and the ratio of the index of full day employed persons $(L)$ to the labour force $(F)$ variables serve as proxies of the GDP and unemployment variables. This change allows avoiding nonlinearities that encumber the calculation of the impulse reaction function of the macroeconometric model, caused by log-linear behavioural equations used together with the linear GDP or unemployment rate identity. These proxies highly correlate with the aimed variables, and, in fact, their usage even increases the statistical significance. The impact on the GDP in the model is obtained then as a sum of the effects on its expenditure components, i.e. $Y=C+G+I+X-M$. 
All the model flow variables (exports, GDP, gross investment and gross output, imports, private and public expenditure) are in real terms and are expressed in total as is provided in the national accounts. GDP deflator, export price as well as import price indices are expressed in litas - as perceived by the Lithuanian producers - and calculated as the implicit price deflators using the national accounts data. Wages are nominal as is the short-term interest rate on loans - the nominal interest rate was used in the model instead of the real one because the later was insignificant and very sensitive to sample changes. The standard labour force data are used, but, in order to avoid labour hoarding and labour shedding problems, for employment data the conventional number of workers, who worked the full day, was utilized instead of the standard employment figures - the statistical significance of the employed variable was seemingly better too. All the data were obtained from the STAS database of the Statistics Lithuania.

\subsection{Analysis of Integration Order and Cointegration Testing}

In order to identify the order of integration of variables the usual ADF test (for its description and comparison with other testing alternatives see Maddala and Kim, 1998) was applied to seasonally adjusted separate members $i$ of the vector $Z_{t}$.

Testing has revealed that, at the 5 percent significance level, the null hypothesis could not be rejected that all the variables in $Z_{t}$ are integrated of order one $\left(\forall i Z_{i t} \sim I(1)\right.$ ). The hypothesis is strongly rejected that the respective components have two unit roots. Therefore the cointegration property can be investigated.

Data shortage usually results in a failure to build a reliable VAR model; therefore the widely applied Johansen test (see Johansen, 1988) is not applicable here. Instead, we employ the two-step Engle-Granger (EG) approach (see Engle and Granger, 1987). It is dangerous to apply the EG procedure directly, however, because in small samples (e.g. near 30 observations) the ordinary least squares (OLS) estimates of the static first-step cointegration regression might be highly biased due to dynamics in the error term (see Banerjee et al., 1986), for instance, caused by incorrectly specified lags in cointegrating relationship. As a consequence, the inference on cointegration might be distorted. To overcome the problem arising due to incorrectly specified lags in the cointegrating relationship, we employ the following strategy.

Assume that the cointegration of a variable $Y_{1, t} \sim I(1)$ with the vector of variables $Z_{t}^{* \prime}=\left(Y_{t}^{* \prime}: X_{t}^{\prime}\right)$ is tested, where $Z_{t}^{*}$ consists of the same components as $Z_{t}$, except that $Y_{1, t}$ is excluded out of $Y_{t}^{*}$ and the remaining variables might be shifted in time. Then the first step modified of the EG procedure would be to obtain the OLS estimates in regression

$$
Y_{1, t}=-\gamma_{1}^{\prime} Y_{t}^{*}+\beta_{1}^{\prime} X_{t}+d_{1, t}+v_{1, t}
$$

where $\gamma_{1}^{\prime}$ and $\beta_{1}^{\prime}$ are the respective vectors of the parameters including, possibly, the respective elements of matrices $\Gamma$ and $B ; d_{1, t}$ denotes a deterministic part, consisting of a constant and a trend term. The time shifts (up to four lags) of $Y_{t}^{*}$ (and $X_{t}$ implicitly) components are based on the minimization of the residual sums of squares in (3). At the second step, the standard ADF test is used to check for the stationarity of residuals of the estimated regression (3), using the relevant critical values. 
It should be noted that under the null of no cointegration changing the lag structure of variables of the first-step regression does not have any influence on the asymptotic distribution of the parameter estimates. In small samples the modified procedure might increase the power of the test considerably, however, when the cointegration regression error dynamics is caused by the incorrectly specified lag structure in the cointegrating regresion.

The application of the modified EG procedure, in our case, has revealed that, at the 5 percent significance level, the potential cointegrating relationships as specified using economic reasoning could be treated as cointegrated. The standard EG procedure without taking into account the relevant lag structure of $Z_{t}^{*}$ gave different results - four times it did not reject the null of any cointegration at the same significance level.

\subsection{Specification of Changes and Model Adequacy Analysis}

The next problem after defining the long-run cointegrating relationships is to specify the part of changes in the conditional SVECM. This task is split into two steps.

First, the preliminary specification of the model is made utilising economic restrictions, namely, the related disequilibrium term $u_{t-1}$ is included and the respective contemporaneous and lagged changes of endogenous and exogenous variables of the economic specification are added. It should be noted that the lagged variables in (3) mean that the cointegrating relationship error $u_{t}$ in (1) is related to the vector of errors in (3) as follows ${ }^{2}$

$$
v_{t}=u_{t}-(\Gamma-I) \Delta^{*} Y_{t}
$$

where $\Delta^{*} Y_{t}=Y_{t}-Y_{t}^{*}$. Therefore, in (2) the term $v_{t-1}+(\Gamma-I) \Delta^{*} Y_{t-1}$ stemming from (4) is used straightforwardly instead of $u_{t-1}$.

As in the second step, using the forward stepwise procedure, the remaining dynamic terms $A(L) \Delta Z_{t}$ that are significant at the 5 percent significance level have been selected from changes of all the remaining contemporaneous and lagged endogenous and exogenous variables. If the forward-stepwise procedure gave only a minor increase in adjusted $R^{2}$ or the preliminary specification were more stable and robust to testing, then the preliminary specification would be used further. Otherwise, a revised version of SVECM is selected.

The model adequacy is tested using the Ljung-Box Q, White, Jarque-Berra, RESET and CUSUM tests that are fit to test for autocorrelation, heteroscedasticity, and nonnormality of the error term, and for possible nonlinearities and structural breaks, respectively (for description of the tests see, e.g., Johnston and DiNardo, 1997).

It should be also noted that all the insignificant terms are dropped and, in order to reduce the number of parameters, the hypotheses for some parameters are tested as to their equality, e.g. whether some short-term and long-term terms cancel out or the effects of seasonal dummies $s_{q t}(q=1, \ldots, 4)$ are equal, where $s_{q t}=1$ in quarter $q$ and $s_{q t}=0$ otherwise. If such a hypothesis could not be rejected, the respective variables were joined in an adequate way.

\footnotetext{
${ }^{2} v_{t}=\operatorname{diag}\left(Y_{t}\right)+(\Gamma-I) Y_{t}^{*}-B X_{t}=\operatorname{diag}\left(Y_{t}\right)+(\Gamma-I) Y_{t}^{*}-B X_{t}+\Gamma Y_{t}-\Gamma Y_{t}=u_{t}-(\Gamma-I) Y_{t}+$ $(\Gamma-I) Y_{t}^{*}=u_{t}-(\Gamma-I) \Delta^{*} Y_{t}$.
} 


\subsection{Exogeneity Testing}

The correct assumptions on strong exogeneity (see Engle et al., 1983) of the a priori assumed exogenous variables are needed, at least in the long run, in order to get correct dynamic in- and out-of-sample forecasts (see e.g. Pagan, 1989; Clements and Hendry, 2003). Due to the log-linearity of the model, a good forecasting performance of the model is needed in order to calculate the reliable impulse response functions, too. All this requires testing at least for the so-called long-run strong exogeneity, implying that in the co-integration relationship only the dependent variable adapts to the long-run relationship.

Exogeneity is tested using the standard Johansen (1992) procedure, i.e., the results of the relevant unrestricted and restricted VECM models are compared, using the likelihood ratio test. In all cases the statistical analysis does not reject the validity of assumptions on the long-run exogeneity of exports, interest rates, foreign prices, and labour force.

\section{Statistical Identification and Adequacy Testing}

The implementation of the methodology, described in section 3, resulted in the specification of equations presented below. The final estimation of the model is performed in the conditional SVECM form. The parameter estimates are based on quarterly 1995:1-2004:2 data. Five out of eight behavioural equations $(C, I, O, P, W)$ comprise a simultaneous system and three equations $(G, M$ and $L)$ are recursively defined. To obtain the consistent estimates, the simultaneous equation system is estimated using the two-stage least squares procedure (the instruments were selected using the statistical forward selection procedure from the set of all predetermined variables in the four simultaneous equations investigated) and the recursive part is estimated using OLS.

The $t$ statistic is provided in brackets and under each of the equations the results of model adequacy testing are presented. Respectively, the adjusted coefficient of determination, Durbin-Watson statistic, and the actual probability level of the null hypotheses of uncorrelated (Ljung-Box $Q_{4}$ ), homoscedastic (White), and a normally distributed (JarqueBera) error term, as well linearity of the model $\left(R E S E T_{2}\right)$ are presented. In addition, the null of parameter stability have been tested and could not be rejected at the 5 percent significance level, using the CUSUM test. The co-integration error term, as specified in the co-integration analysis phase, is provided in square brackets.

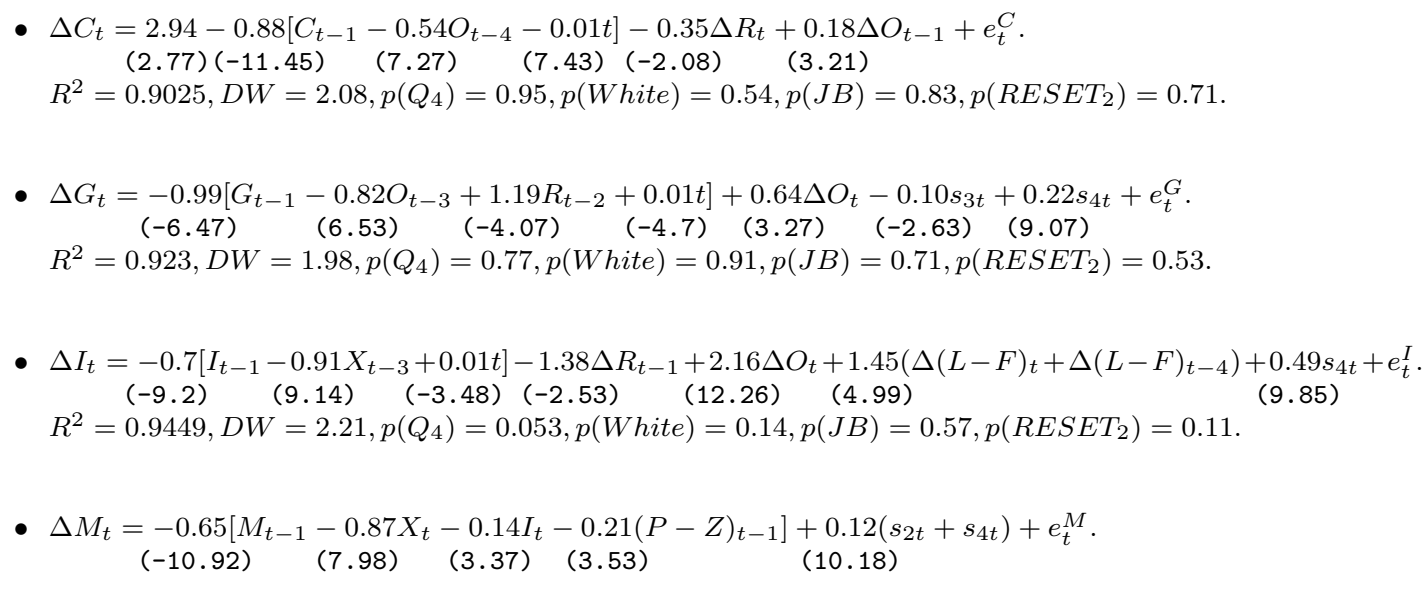




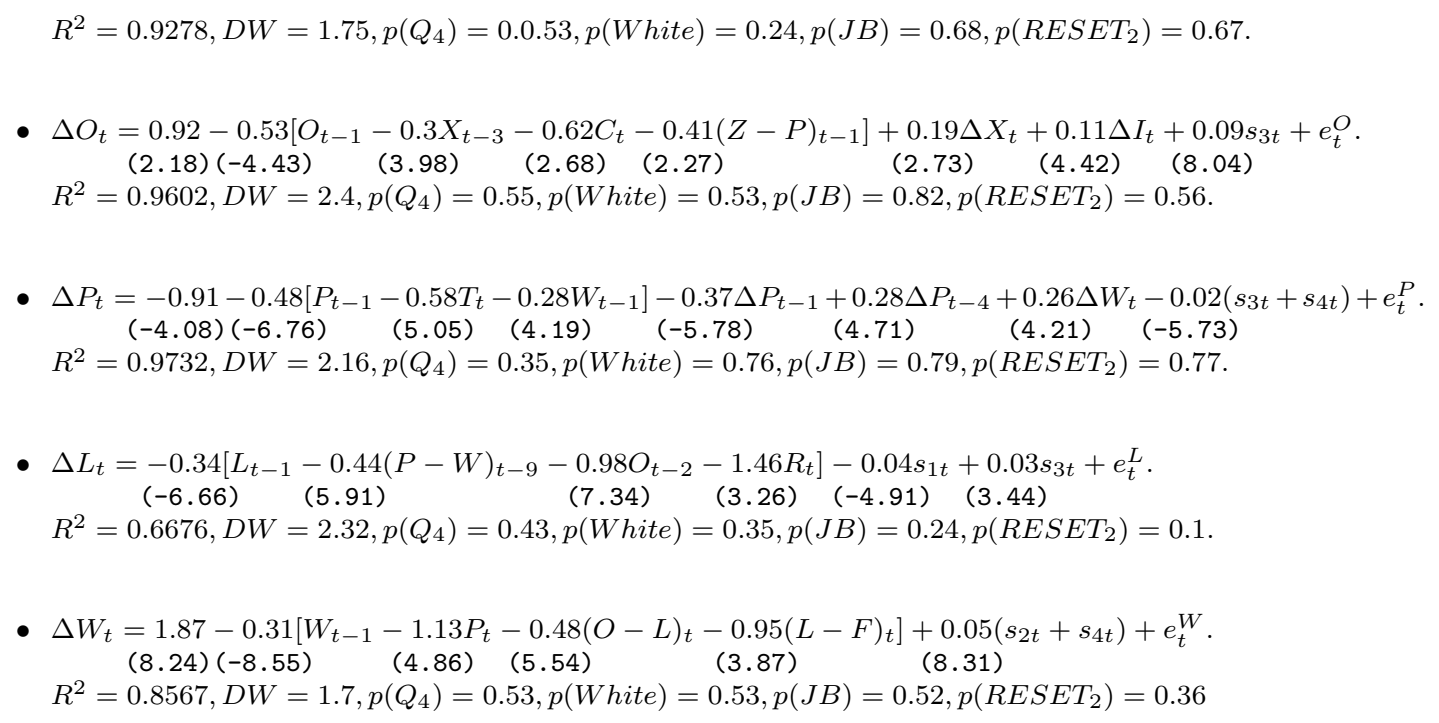

When the standard critical values are applied, all parameters are significant at the 5 percent significance level and there are no significant model adequacy problems. The out-of-sample forecasting performance is evaluated by estimating the model, using the 1995:1-2002:4 data and forecasting the dynamics of endogenous variables in quarters 2003:1-2004:2, based on the actual data of exogenous variables. It should be noted that all the coefficients remained significant when estimated using the 1995:1-2002:4 period data. This means that the same model structure would be not rejected when building the model, based on this sample. The diagrams presented below plot the changes of the actual and multi-step forecasted endogenous variables.

It could be seen that the out-of-sample conditional forecasts track the changes of variables quite well. It should be stressed, however, that the model forecasted somewhat lower levels of consumption and, respectively, of gross output and the GDP. The higher levels of employment and wages were forecasted though. The likely cause of such misalignment might be due to the effects of unofficial economy and increasing borrowing that the model is not able to capture.

It should be noted in addition, that the residuals of the developed structural model are contemporaneously uncorrelated - at the 5 percent significance level the null hypothesis of correlated errors was rejected; therefore for the impulse response analysis there is no need to impose any additional identification restrictions.

\section{Application of the Model}

Based on time series models and expert information, the forecasts of exogenous variables have been developed. Using these results, the conditional forecasts of the model have been obtained for the period 2004:3-2005:4. The forecasted growth rates of the main variables in 2005 are presented in Table 2.

The left part of the table presents the conditional forecasts when the impact of the EU funds is not accounted for. As could be seen, the growth rate of the Lithuanian economy is estimated to slow down to 4.4 percents, and this would happen mainly due to the fall in 

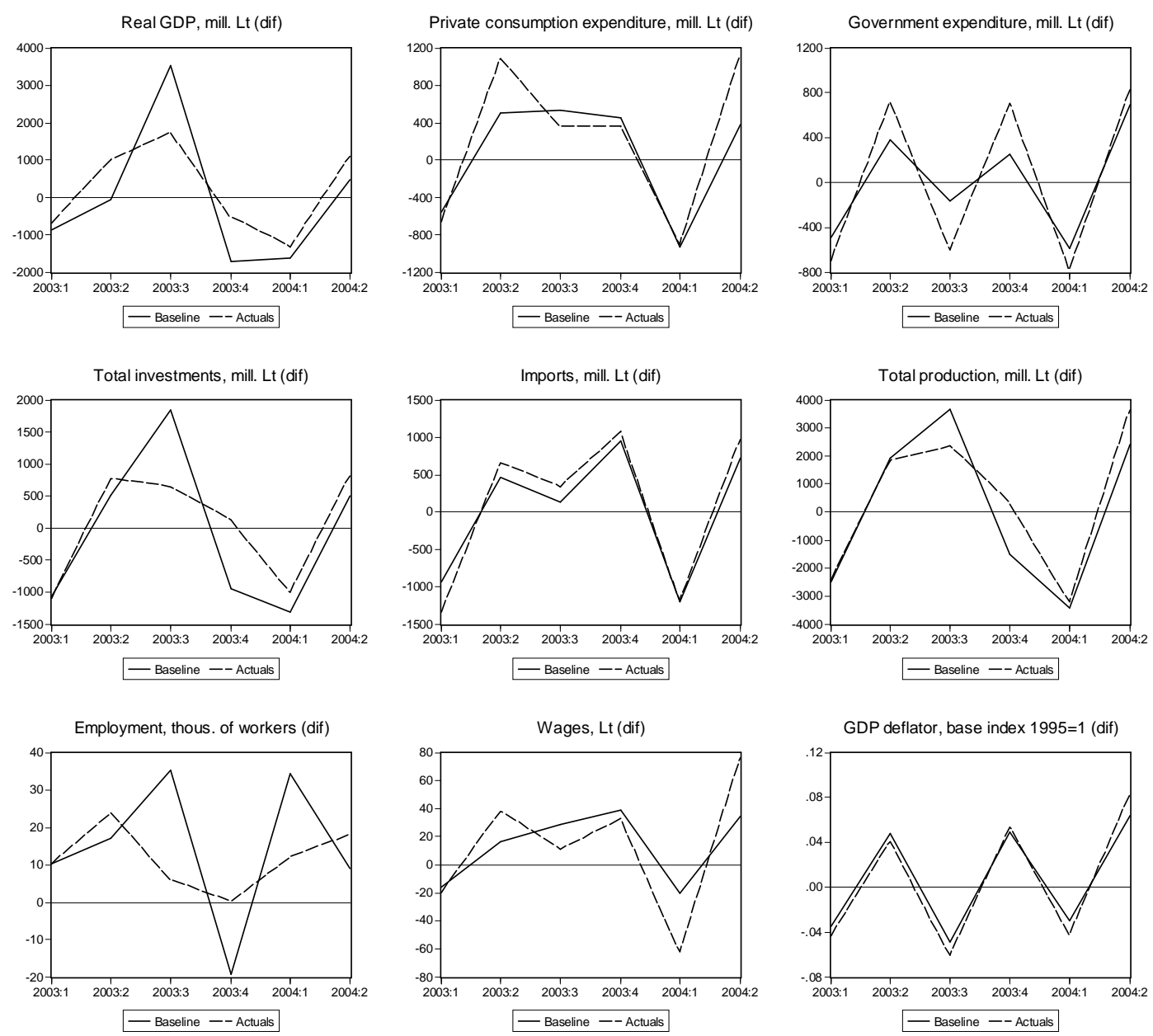

Figure 1: Forecasted (baseline) and actual values of the endogenous variables (first differences)

investments that were booming in the previous years because of increased construction activities and borrowing. However, recently the top of the investment cycle has been passed and they could really go down, at least, the interest rate sensitive part would drop as the short-term and long-term interest rates are expected to increase by about two percentage points in year 2005 .

Taking into account the impact of the EU funds (see the middle term of Table 2) gives a different picture however. In 2005, the budgetary and related inflow from the EU are expected to reach 2.676 billions of Litas and the contribution of Lithuania to the EU budget will be about 0.766 billions of Litas meaning that the net primary impulse of the EU funds will amount to 1.910 billions of Litas. These additional funds will definitely have an impact on the Lithuanian economy. By analogy with Directorate (2001) that has made an assumption that 80 percents of the net funds will take the form of investments and 20 percents will go to consumption, we simulate the potential impact of the EU funds. As could be seen from the second part of Table 2, the EU funds are expected to foster the real GDP growth by 2.2 percentage points compared to the former scenario and the increase 
Table 2: Forecasted yearly growth rates in 2005 without and with the impact of the EU funds

\begin{tabular}{|l|l|l|l|}
\hline Variables & $\begin{array}{l}\text { without } \\
\text { the impact }\end{array}$ & $\begin{array}{l}\text { with } \\
\text { the impact }\end{array}$ & $\begin{array}{l}\text { the } \\
\text { difference }\end{array}$ \\
\hline Real GDP & 4.4 & 6.6 & 2.2 \\
\hline Private consumption expenditure & 9.9 & 10.4 & 0.5 \\
\hline Government expenditure & 5.8 & 8.2 & 2.4 \\
\hline Gross investments & -2.8 & 7.8 & 10.6 \\
\hline Imports & 4.8 & 6.5 & 1.7 \\
\hline Gross output & 7.2 & 8.1 & 0.9 \\
\hline Nominal GDP & 7.6 & 10 & 2.4 \\
\hline Employment & 3.9 & 4.2 & 0.3 \\
\hline Wages & 8.3 & 8.7 & 0.4 \\
\hline GDP deflator & 3.2 & 3.4 & 0.2 \\
\hline
\end{tabular}

in the real GDP is mainly due to stimulated investments.

\section{References}

A. Banerjee, J.J. Dolado, D.F. Hendry, and G.W. Smith. Exploring equilibrium relationships in econometrics through static models: some Monte Carlo evidence. Oxford Bulletin of Economics and Statistics, 48(3):253-278, 1986.

O. Basdevant and S. Hall. The 1998 Russian crisis: could the exchange rate volatility have predicted it? Journal of Policy Modeling, 24(2):151-168, 2002.

O. Basdevant and U. Kaasik. Analyzing the prospects of Estonia using a macroeconomic model. Eastern European Economics, 41(4):38-71, 2003.

H.P. Boswijk. Efficient inference on cointegration parameters in structural error correction models. Journal of Econometrics, 69(1):133-158, 1995.

M.P. Clements and D.F. Hendry. Evaluating a model by forecast performance. Mimeo, Department of Economics, University of Warwick and University of Oxford, 2003.

L. De Haan, A. Naumovska, and H.M.M. Peeters. MAKMODEL: a macroeconometric model for the Republic of Macedonia. De Nederlandshe Bank research memorandum WOandE, (655), 2001.

Directorate. The Economic Impact of Enlargement, Number 4. Directorate General for Economic and Financial Affairs, 2001.

R.F. Engle and C.W.J. Granger. Co-integration and error correction: Representation, estimation, and testing. Econometrica, 55(2):251-276, 1987. 
R.F. Engle, D.F. Hendry, and J.-F. Richard. Exogeneity. Econometrica, 51(2):277-304, 1983.

C.A. Favero. Applied Macroeoconometrics. Oxford University Press, Oxford, 2001.

O. Havrylyshyn. Recovery and growth in transition: A decade of evidence. IMF Staff Papers (Special Issue), 48:53-58, 2001.

D.F. Hendry. Econometrics. Alchemy or Science? Oxford University Press, New York, 2000.

S. Johansen. Statistical analysis of cointegration vectors. Journal of Economic Dynamics and Control, 12:231-254, 1988.

S. Johansen. Cointegration in partial systems and the efficiency of single-equation analysis. Journal of Econometrics, 52(3):389-402, 1992.

J. Johnston and J. DiNardo. Econometric Methods. McGraw-Hill, New York, 4th edition, 1997.

V. Kvedaras. Macroeconometric Modelling of Impact of the EU Integration on the Lithuania's Economy. Dissertation, Vilnius University, Faculty of Economics, Vilnius, 2004.

G.S. Maddala and In-Moo Kim. Unit Roots, Cointegration and Structural Change. Cambridge University Press, Cambridge, 1998.

J.S.L. McCombie and A.P. Thirlwall. Economic Growth and the Balance of Payments Constraint. St. Martin's Press, New York, 1994.

A.R. Pagan. On the role of simulation in the statistical evaluation of econometric models. Journal of Econometrics, 40:125-139, 1989.

D. Qin. On macro modelling of transition economies: with special references to the case of China. In S. Cook, editor, The Chinese Economy in Transition, pages 243-256. MacMillan, 2000.

R. Rudzkis and V. Kvedaras. Econometric modeling of the impact of the EU integration on the Lithuanian economy. In S. Aivazian, P. Filzmoser, and Yu. Kharin, editors, Proceedings of the 7th International Conference "Computer Data Analysis and Modeling”, Minsk, September 6-10, 2004, Vol.2, pages 33-40. BSU, Minsk, 2004.

J. Sutton. Sunk costs and market structure: price competition, advertising, and the evolution of concentration. MIT Press, Cambridge, 1991.

K. Weyerstrass, G. Haber, and R. Neck. SLOPOL1: A macroeconomic model for Slovenia. International Advances in Economic Research, 7(1):20-37, 2001. 
Authors' addresses:

Prof. Dr. Rimantas Rudzkis

Applied Statistics Department

Institute of Mathematics and Informatics

Akademijos. 4-604

LT-08663 Vilnius

Lithuania

Tel. +370 5 2109-327

Fax +370 52729209

E-mail: rudzkis@ktl.mii.lt

http://www.mii.lt/index.php/

Dr. Virmantas Kvedaras

Department of Quantitative Methods and Modelling

Vilnius University

Sauletekio al. 9/II-813

LT-10222 Vilnius

Lithuania

Tel. +370 5 2472-111

Fax +370 5 2366-284

E-mail: vkved@takas.lt

http://www.ef.vu.lt/index.php?sid=english/ 